\title{
Recapitulation of the anti-Idiotype antibodies as vaccine candidate
}

\author{
Ahsan Naveed ${ }^{1 *}$, Sajjad Ur Rahman ${ }^{1}$, Muhammad Imran Arshad ${ }^{1}$ and Bilal Aslam²
}

\begin{abstract}
The foreign antigen that enters into the body is detected by the immune system through antigen presenting cells leading to the production of antibodies. The use of anti-idiotype antibodies is a new way to excite the immune response that identifies and eliminates the foreign antigens entered into the body. These Anti-idiotype antibodies have the ability to decrease the non-specific binding of the antigenic protein epitopes because of high specificity for the antigenic determinants. The anti-idiotype antibodies attach to the paratope of idiotype antibody and stimulate a precise immune reaction same as that of external antigen. The anti-idiotype antibodies are the peerless therapeutic candidate as they mimic the antigenic structure and potentiate antibody and cell-mediated immunity. Even in the absence of foreign antigen, these anti-idiotype antibodies have the potential to provide long-lasting immunity. The present review is about immune regulations by anti-idiotype antibodies with some success therapeutic stories.

The previous research analysis is evidence of anti-idiotype antibodies as an excellent candidate for the development of both human and animal vaccines although it has some gaps that are needed to be addressed.
\end{abstract}

Keywords: Anti-idiotype, Immunity, Vaccines, Antigens

\section{Background}

The Immune system is strong defense against invading pathogens, a number of different ways are adopted at immune system and pathogen interface. The one is antibodies produced in response to the foreign antigen to combat the ailment and provide a lasting immunity. The antibody are documented to be used in various disease therapies as well, antiidiotype antibodies are proved to have therapeutic potential in certain cancers. Their use was discouraged due to some of the issues regarding period of immunity and physiological effects. Still the achievements of antiidiotype monoclonal antibodies against bacterial and viral disease and cancer treatments cannot be denied. The present review is to highlight the importance of antiidiotype antibodies vaccines in viral and bacterial diseases. Furthermore, there are some gaps in the research that are needed to be addressed for better applications of antiidiotype antibodies as vaccines and in the field of oncology for curative purpose.

\footnotetext{
* Correspondence: ahsannaveed.uaf@gmail.com

1 Institute of Microbiology, University of Agriculture, Faisalabad 3840, Pakistan Full list of author information is available at the end of the article
}

\section{Structural analysis of antibody}

The immune system starts producing antibodies whenever it recognizes any foreign element in the body. Approximately hundred antibody-forming clones may be stimulated by immunization with a small, chemically well-defined molecule. A specific antibody is produced by each clone; each antibody possesses a unique sequence of the amino acid within its variable region [1]. The epitope is a site on the antigen with which an antibody binds. There may be many such epitopes on the surface of an antigen. This binding of antigen and antibody is extremely specific and generally of great affinity. Many of the biological systems as assaying the proteins, cell separation and quantitative analysis of microbes use antibodies as molecular probes. Antibodies or immunoglobulin molecules are classified into five groups, each of which is similar in fundamental molecular patterns. There are four discrete chains of polypeptides in each immunoglobulin molecule two indistinguishable heavy chains joined by disulfide bonds to two indistinguishable light chains. Each chain comprises variable domains and constant domains. All antibodies of a given class are identical in their constant domains [2]. The specificity of 
antigen recognition and extreme diversity of antibodies is due to the dissimilarities in the sequence of the protein of variable domains. For instance, the heavy chain of monomeric antibody molecule IgG is composed of an amino-terminal variable domain $(\mathrm{VH})$ and three constant regions $(\mathrm{CH} 1, \mathrm{CH} 2$, and $\mathrm{CH} 3)$ which specify the common features of the precise class of immunoglobulin. Each light chain for Immunoglobulin G (IgG) is comprised of two domains: variable domain $(\mathrm{VL})$ and constant domain (CL) where VL has an amino-terminal while $\mathrm{CL}$ contains a carboxy-terminal. For the formation of a variable region, one $\mathrm{VL}$ domain joins with one $\mathrm{VH}$ domain, encompassing particular and specific properties of antigen-binding [3]. The overall structural organization of both of these domains is similar. Three hypervariable regions are intermingled with four framework regions in $\mathrm{V}$ domain at the primary amino acid string. The order of amino acid in hypervariable regions of $\mathrm{V}$ domains are diverse while those of framework regions are relatively conserved in various antibody molecules. The hypervariable loops develop from the stereo configuration of framework regions in a $\mathrm{V}$ domain bend into an arrangement of dissimilar p-sheets. Six hypervariable loops are found in an integral $\mathrm{V}$ region, three from the light chains and three from the heavy chains. Turn structures of different conformations are often reversed by these loops [4]. Non-refined structure of $\mathrm{V}$ regions and effect of orderly assortment which generate antibody specificities are due to variability in arrangements of loop sizes from antibody to antibody. The co-crystallization of antibodies with $\mathrm{Ag}$ indicated the involvement of these remarkably unstable regions also termed as complementarity determining regions or CDRs in the binding of Antigen (Ag). The role of CDRs in contacting the antigen has been confirmed by the latest studies which used the artificial peptides derived from antibody CDRs, and it has been indicated that the chemical nature of particular amino acids is critical in determining the binding specificity [5].

\section{Concept of Idiotype and anti-idiotype antibodies}

A monoclonal antibody contains precise or idiosyncratic variable region, and properties of the $\mathrm{V}$ region are responsible for determining the 'idiotype (Ids)' of the antibody. Whereas, the exact meaning of idiotype is quite complicated, it may be considered as, "those characteristics of the antibody which is responsible in making its variable region precise". Anti-idiotype (Anti-Ids) is that antibody which attaches to the idiotypic variable domains of an additional antibody. Idiotope is that particular position on an idiotype which binds by some anti-ids as shown in plate 1 (A) [6]. The idiotype of an antibody may be considered as a collection of idiotopes. In the meantime, few anti-idiotypes attach to the idiotype in the same way a unique antigen attaches, they may have some antigenic features [6]. Generally, animals are immunized with antibodies particular for a given antigen for the development of anti-idiotypes. Biochemically antibodies are defined on the basis of their idiotypic counterparts [7]. Functional characteristics of antibodies particularly idiotype expression and identification of antigen are determined by the structural organization of antibodies. Random coil and reverse turn loops both are recognition positions and may be antigenic. Subsequently, idiotypic sites and combining sites of antibody overlap extensively by definition. It has been predicted that idiotypic sites exist inside the framework regions, and inside the variable region they play the role to reverse turn structure and the studies confirmed that framework regions contribute as recognition sites in the expression of idiotype [8]. Anti-idiotypes have the ability to block the binding of antigen to vaccinating-idiotypeexpressing antibody. This blocking of antigen binding by the anti-idiotype does not indicate that anti-idiotype being an antigen attaches in the same way or even to the same place. Binding of antigen can be blocked if an antiidiotype attaches to an idiotope on a place close to or covering the antigen binding site as in plate $1(\mathrm{~B})$, but anti-idiotype does not completely act as the antigen. Such anti-idiotype may possess remarkable features as in immune expression it regulates the expression of idiotype, in binding interactions it may not act like an antigen. To analyze that an anti-idiotype act as the antigen, binding of antigen and anti-idiotype to both the additional substance and idiotype is often examined, mainly in analyses of receptor-ligand interactions which uses anti-idiotypes [9]. A number of ligands including the cytomegalovirus receptor, insulin, the formyl chemotactic peptide fMet-Leu-Phe, retinol binding protein, mammalian reovirus type 3 , $\beta$-adrenergic catecholamines and $\beta-1 \mathrm{H}$ globulin receptor has been produced by anti-ids anti-receptor antibodies that identify the receptors, particularly for these ligands [10-14]. For blocking of ligand-receptor interactions the common approach is to develop $\mathrm{Ab}$ to the ligand. The antibodies having idiotype may be used to develop anti-idiotypes that act as the ligand because these antibodies in interaction with the ligand are 'receptor-like'. The anti-idiotypes produced in this way are read by their capability to bind both receptor and idiotype, this binding is expected in a way more specific of the ligand. Immunologists called these antiidiotypes 'internal image' anti-idiotypes because they exhibit an image of antigen/ligand contained in animal's internal collection of antibodies [15].

\section{Potentiation of immune response by the Idiotype/ anti-idiotypes}

The immune response is regulated by a network of interactions that were previously considered only the 
interaction of an antigen or antibody. The scientist concluded that idiotypic determinants are basic components of this network. They do not find any reason that if antibodies have a vast array of antigenic combining site why they are not themselves recognized as antigens [16]. He proposed that the immune system is a mystery because of the interconnected network of idiotype and antiidiotype antibodies. According to the idiotypic network theory, the idiotype of an antibody has its anti-idiotype that has the capacity to identify the idiotype of another antibody similarly the idiotype of every antibody is recognizable by the idiotype of another antibody as in plate $1(\mathrm{c})$. So, such an interconnected network is involved in maintaining the self-regulation of the immune system [17]. Idiotypes, the portion of antibodies where antigenic epitopes bind is also known as antigen determining factor in the variable section of either the $\mathrm{B}$ and $\mathrm{T}$ lymphocytes or phenotypic markers to variable part of genes [18]. Lymphocytes are found in dynamic equilibrium primarily; this equilibrium is facilitated by idiotypic interactions. This dynamic equilibrium is disturbed when the antigen is directed and provoke an immune response. Particularly, immunization with anti-Ids earlier to Ag introduction has resulted in either increased expression of $\mathrm{Ag}$ and Id binding activity or destruction of Id-positive Ag-binding molecules [19]. Subsequently, the immune response can be suppressed or enhanced by the pretreatment of anti-Id depending on the antigen system. Idiotype network was further reinforced by the indication that characterization of Id receptors which are found in both $\mathrm{B}$ and $\mathrm{T}$ lymphocytes and development of Id-specific suppressor or helper $\mathrm{T}$ cells can be induced after administration of anti-Id [20]. In malignancies and various infectious diseases, anti-ids $\mathrm{Ab}$ has been examined and probed as ameliorative antibodies [21]. Afterwards, these anti-ids were successfully used as surrogate Ag, called Ab2beta the internal image antigen, hence swap the place of primary antigens used as the vaccinating agent. Anti-ids antibodies were classified as Ab2alpha, Ab2beta and Ab2gamma, exhibiting their biological role as ameliorative antibodies. Ab2alpha and Ab2gammas are non-internal images, the former is biologically non-functional antibodies but later is biologically effective [22]. In previous studies, the auto-anti-Id has been identified and characterized during the natural course of immune reactions. Thus the concept that network of idiotype play role in immune reactions to an antigen has been supported by scientific evidence when the antibodies derived from the animal were injected in same animals and it started developing anti-antibodies [23]. The pathogenic auto-antibodies express the idiotypes which might also be utilized as disease markers.

Idiotypes are specific for self and foreign antigen, regulate the responses to antigen and tend to be sometimes referred to as regulatory idiotypes. In immunological homeostasis, an equilibrium exists between primary antibody the idiotype antibody (Ab1) and secondary antibody anti-idiotype (Ab2) clones, where Ab2-reactive lymphocytes control the formation of Ab1. In autoimmune diseases when self or foreign antigen is encountered by a living thing, equilibrium is moved in support of the creation of Ab1 clones which step to the antigen. That escalates the creation of Ab2 antibodies by generating more Ab2- clones, Ab2-Ab controls the functions and variety of Ab1-producing $\mathrm{B}$ cells, leading to decreased Ab1 [24]. In a number of model systems, the idiotypic-specific T-cell clones have already been described that can identify and interact to idiotypic determinants on $\mathrm{B}$ cells, these $\mathrm{T}$ cell clones constitute numerous functional categories of $\mathrm{T}$ cells like regulatory cells with suppressor function or helper of effector cells which mediate delayed-type hypersensitivity or cytotoxic or contact allergic reactions. Peptide fragments of idiotypic determinants on the framework of major histocompatibility class II (MHC class II) molecules existing on antigen presenting cells (APCs) are recognized by these idiotype-reactive $\mathrm{T}$ cells that are $\mathrm{MHC}$ regulated. MHC class II molecules present on B cell surface is involved in presenting and processing of immunoglobulin present on that B cell. The B cells are triggered following the crosslinking of immunoglobulin receptors on $B$ cell surface and process the idiotype for presentation [25]. Various groups have termed anti-idiotypic $\mathrm{T}$ cells specific for conformational idiotype but are unpredictable with the existing patterns of T-cell activation. However, this specific binding might possible in case a conformational idiotype is processed and presented to $\mathrm{T}$ cells in ways that conserved its structure. Then in the clear presence associated with additional antigen-specific conventional helper $\mathrm{T}$ cell, these cells could boost the creation of idiotype-bearing antibody [26].

\section{Applications of anti-idiotype antibodies in disease therapy}

Anti-id vaccines have recently been produced in rodents for the immunization against various pathogens such as Streptococcus pneumonia, Brucella abortus, and Escherichia coli. [27]. In studies, the anti-idiotype vaccine against Pasteurella multocida was well prepared from outer membrane protein (OMPs). It has recently been reviewed that OMPs-anti-idiotype vaccine provokes immense amount of antibody titers (geomean titers-GMT) ascertained by applying indirect haemagglutination (IHA) test that gave $100 \%$ protection against the challenge with the homologous strain of P. multocida [28]. Chlamydia trachomatis a pathogen that triggers the genitourinary infections in human, it is evident that the anti-Id (monoclonal Ab2) vaccine is defensive against a 
human biovar of $C$. trachomatis in $\mathrm{C} 3 \mathrm{H} / \mathrm{HeJ}$ mice. In research, the $\mathrm{C} 3 \mathrm{H} / \mathrm{HeJ}$ mice that are allogeneic to the origin of monoclonal anti-idiotype antibodies (mAb2) $(\mathrm{BALB} / \mathrm{c})$ were given a topical genital challenge with $C$. trachomatis and significant protection against the disease was evaluated [29].

Anti-idiotypic vaccines have also been developed in rodents for a number of viruses including reovirus, rabies virus, murine mammary tumor virus (MMTV), murine leukemia virus, hepatitis B virus (HBV) and human immunodeficiency virus (HIV). In line with the literature both humoral and cellular immunity has been observed against MMTV by immunization with anti-Ids. Hepatitis B surface antigen has been reported to elicit a more robust immune response by making internalimage Ab2 $\beta$ antibodies in HBV [30]. The anti-idiotype antibody can be favorable in the development of vaccines against AIDS virus (HIV). Anti-HIV responses, particularly for glycoproteins (gp40, gp120, and gp160) on HIV, have recently been induced by these anti-Ids [31]. It has been observed that anti-Id when mimicking a normalizing epitope on the glycoprotein B-complex of human cytomegalovirus, acts as a strength antigen and set on the production of specific antibodies against human cytomegalovirus [10]. With all the current understanding of anti-idiotype antibody, the disease in which mucosal associated tissue are central targets like gut or lungs, the use of anti-idiotype may be possible to expand through taking on the oral immunization practice. Besides the protein antigens, anti-Ids can be remarkably used in the development of vaccines against lipid, carbohydrate or nucleic acid epitopes or even drugs. In such cases, anti-Ids are proteins that imitate a non-protein epitope [32]. For parasites as in Schistosoma mansoni, Trypanosoma rhodesiense and Trypanosoma cruzi, rodent anti-Ids have recently been developed. Parasites mostly have epitopes of carbohydrates which is the limiting factor in the vaccine's development because of recombinant technology in the generation of peptide [33]. Anti-Ids can overcome this problem; that have been developed against lipid epitopes. By producing an anti-Id against lipid $\mathrm{A}$, the thymus-independent antigen lipid $\mathrm{A}$ from Eikenella corrodens lipopolysaccharide (LPS) was transformed into a thymus-dependent immunogen. The experimental results indicated the mice that were previously immunized with anti-Ids cope with the disease when a lethal dose of LPS was given to them [34].

Curative access to varied sort of cancers is primarily gained through the idiotypic network hypothesis, involving immunization achieved through antitumor Ab1 antibodies bringing about the production of anti-idiotypic antibodies (Ab2), or given anti-idiotypic antibodies (Ab2), which be working as anti-idiotypic vaccines which could functionally curtail the tumor-associated antigens
(TAA) and evoke strong immune response to tumor cell [35]. A limitation of immunotherapy achieved with TAA will be an induction of comparatively low immunogenicity of tumor antigens. Moreover, anti-idiotypic antibodies can mimic either non-protein or protein antigens. The two possible vaccinating antibodies whether it's Ab1 or Ab2 the end result will be the anti-anti-idiotypic response (Ab3) produced because of the host from the tumors that need antibody-dependent cell mediated cytotoxicity (ADCC), and further cell-mediated cytotoxic pathways including natural killer cells and cytotoxic $\mathrm{T}$ cells [36]. Once immunization is performed against TAA with antibodies that provoke internal mage antibodies they resulted in the clonal development of cells that play in the antitumor activity. This approach is quite effective for various sort of cancers therapies. A powerful anticarcinoembryonic antigen (anti-CEA) response happens to be cited with the patients using a surgically resected colon after vaccination with CeaVac that may be an antiidiotypic antibody and inner picture of CEA [37]. The curative potential of anti-idiotype antibodies in some patients exhibited the clinical improvements by using a tumor-specific mechanism that needs ADCC, idiotype and antigen-specific result of CD4 helper T cell. A murine monoclonal anti-idiotypic antibody (Ab2), labeled as ACA125, produced antitumor reactions and reduced development of disease using a minimal rate of undesirable effects in patients with ovarian cancers [38]. Idiotypic network interactions are likewise employed in aiding the cancerous melanoma, research trials using ADCC approaches in patients with small cell carcinoma of the lung showed the recovery of patients using the antiidiotypic antibody (Ab2) in therapy that resemble the disialoganglioside GD2 and initiate the production of anti-anti-idiotype antibodies (Ab3) and reacted particularly with tumor cells [39].

Apparently, in the eradication of cancer, anti-Ids are proposed against distinctive idiotopes on $\mathrm{B}$ or $\mathrm{T}$ cell cancers as in leukemia, myelomas or lymphomas [40]. For the induction of specific tumor immunity, internal image antibodies having the activity of tumor antigen are conceivable vaccines candidates. These vaccines are intensely valuable to a patient whose primary neoplasms have been removed the threat for the development of the metastases [41]. Immune tolerance considerable problems of cancer therapy, the opposite anti-Id vaccine can easily overcome immune tolerance rather a usual multivalent vaccine comprising of lysates, whole cell or antigen-rich supernatant. Various manipulations of idiotypes for tumor immunity have been reported, with the immunization of anti-idiotypes having internal images of reputed tumor-specific antigen, antitumor immunity has even been provoked in pilot studies [42]. In a xenogeneic host, an oncofetal antigen was introduced for the 
induction of tumor immunity. Thus in mice, the polyclonal antisera can activate both Ab3 and cell-mediated immune (CMI) response to p97 antigen [43]. In mice, an anti-Id was used to generate CMI to a syngeneic chemically promoted sarcoma. The tumor antigen was not a defined molecule and anti-Id was an autoantibody developed by hyperimmunization to the tumor. The idiotypic administrations of tumor immunity have been demonstrated in syngeneic systems with undefined antigenic compounds [44]. The murine anti-idiotypic $\mathrm{T}$ lymphocytes can be engaged in an autoimmune reaction to $\mathrm{T}$ lymphocytes specific fibrosarcoma, and affect a person's immune reaction to the tumor. Anti-Ids were used in vitro to activate the production of $\mathrm{T}$ lymphocytes particularly cytotoxic $\mathrm{T}$ lymphocytes to rat sarcoma cells [45]. Antitumor immunity to colorectal cancer has been induced by anti-Ids. Antitumor antibody response has shown with a polyclonal anti-Id developed against $\mathrm{mAb}$ 17-1A which identifies the antigen linked to coloncancer in clinical trials of human colorectal patients [46]. In melanoma patients' antitumor antibody response can be elicited by the injecting $2 \mathrm{mg}$ of anti-Id mAb MK2-23, that acts as an exact duplication of a high molecular weight human melanoma antigen. Further, the effect of Ids has been analyzed on tumor growth [47]. Usually, there are more questions when immunoglobulins are widely-used as curative agents that encompass the production of high antibody response, in particular when murine anti-ids $\mathrm{Ab}$ is used [48]. Thus the approaches manipulating idiotypic network interactions further offer the efforts toward producing idiotypic and anti-idiotypic vaccines, and also persistent efforts to assess the efficacy of such biological varieties vaccines alone and in conjunction with other treatment regimens to conquer the disease load.

\section{Choice of anti-idiotype as vaccine candidate}

The network theory of idiotypes provides a welldesigned model for the development of vaccines which do not rely on the typical use of exterior antigen as vaccine candidates. Internal Ag vaccines or anti-Id vaccines are expedient by the simple fact that Id structures imitate the nominal antigens on receptors, immunoglobulins and the products of $\mathrm{T}$ cells. Consequently, with this approach, there is no use of external Ag or its fragments in Id-based vaccines. The Id vaccines production may reduce the likelihood of unwanted side effects which are mostly associated with typical Ag vaccines [49]. Anti-Id vaccines provoke a higher immune response of fine specificities than for antigen vaccines. Id vaccines in conjunction with safety also have other biological, practical and monetary advantages than conventional vaccines. Generally, in the development of a vaccine, the need of pure Ag in considerable amounts is often a restrictive economical factor, but Id vaccines do not rely on this factor. Idiotypes vaccines are protein in nature and can be easily handled also to become T-celldependent antigens they can be coupled to effective immunogenic carriers [50]. The development of fully synthetic Id vaccines might be possible by using imperative sequence information accessed from Id hybridomas Ags. In conditions when the response of an immune system is suppressed or immature then T-dependent protein vaccines may become a significant factor. It has been proved from experimental studies that the response to T-cell based Ags develops earlier than the Tindependent response to carbohydrate antigens, furthermore a genetically or acquired unusual immune system reacts well to $\mathrm{T}$-dependent antigens than to $\mathrm{T}$ independent antigens [51]. By the use of a various molecular form of the same antigenic moiety the acquired state of tolerance to one antigen could be battered. In an extensive context as in the immunotherapy of cancer patients who may be immunodeficient to their own tumor, this factor might become a significant respect [52]. Three-dimensional forms of antigens are mimicked by internal image anti-ids and therefore are genetically limited and effective across the species barrier. The antigens can be presented in the various molecular environment. In several model systems including bacteria, parasites, and viruses the immune response (both $\mathrm{T}$ cell and antibody) has been evoked by the ability of $A b 2 \alpha$ and $A b 2 \beta$. Immunization with $\mathrm{Ab} 2 \beta$ which possess the internal image of antigen provides various advantages over vaccinating with typical vaccines [53]. Anti-Ids are not contagious yet can produce an immune response against the pathogen. These kinds of vaccines are also beneficial when it is precarious to take massive amounts of the antigen. These antibodies abate the potential for autoimmune diseases resulting in antibodies that are produced to other epitopes on the antigen. If the lipid, carbohydrates, and DNA are used as epitopes then these vaccines may prove to be helpful [54].

\section{Gap analysis of anti-idiotype antibodies as vaccines}

There are some potential complications in the development of anti-idiotypic vaccines. It is unidentified for how much time the anti-idiotypic immunity can exist. Like other diagnostic or therapeutic antibodies, a human anti-rodent monoclonal antibody (HAMA) response can be developed against the anti-idiotypes. In order to avoid this, humanization of the anti-Ids by the recombinant DNA techniques may be significant. When the antibody is choosing for the vaccination care must be taken, by the reason various anti-Ids developed against the same idiotope can have varied or even antagonistic physiological effects [40]. 
Presently, there is need of randomized clinical trials for antigen-specific immune responses evoked by antiidiotypic antibodies and clinical responses to obtain clinical proof of concept about the validity of immunization approach. Moreover, methodologies should be developed to augment the capacity of anti-idiotype antibodies to induce an improved antigen-specific immune response with the expectation to ameliorate its effects against the antigen [55]. The outcome of idiotypic vaccines is variable under different situations when using the unique Fab, treating patients with lymphoma or reproducing the idiotype through recombinant or hybridomas methodology. Similarly, various potentially fundamental details regarding this immunotherapeutic approach remain to be defined, such as the number of doses and the type of obligatory immune response that it should provoke through vaccination [56].

In many model systems, the curative capability of the anti-idiotypic antibody has long been analyzed. Appropriately determined monoclonal anti-Id $\mathrm{Ab}$ might stand for antigen surrogates though with the constraint that they will not provoke a wide range of anti-antigens compared to the original antigen. Idiotypes stimulate $\mathrm{Ab}$ that will be perfect for binding anti-Id Ab rather than the antigen, since the morphological necessities for excellent binding of anti-Id are not similar but near to the presenting antigen [57].

\section{Conclusions}

With the current understanding and existing therapeutic modalities of anti-idiotype antibodies in various human cancers, the use of anti-idiotype antibodies against bacterial and viral disease therapies is a quite promising achievement. The therapeutic potential of anti-idiotype antibodies can be used in the field of oncology to treat various kind of cancers. As the monoclonal antiidiotype antibodies are good choice against lung cancer and B cell lymphoma. Furthermore the tumor associated antigens may be used to induce strong immune response with minor side effects instead of chemotherapy or radiotherapy. Although, initially anti-idiotype antibodies were used as a curative agent against certain diseases in human after successful laboratory trials the need is to promote anti-ids as vaccines especially in animals because they are non-infectious protein in nature. Furthermore, the immunoprophylactic potential of anti-idiotype vaccines is needed to be evaluated under field conditions to characterize their effects in animals.

\section{Abbreviations}

Ab1: Antibody (Ab); Ab2: Anti-Idiotype (Anti-Ids); Ab3: Anti-Anti-Idiotype (Anti-anti-lds); ADCC: Antibody-dependent cell mediated cytotoxicity; Ag: Antigen; anti-CEA: Anti-carcinoembryonic antigen;

CDRs: Complementarity determining regions; CMI: Cell-mediated immune response; HAMA: Human anti-rodent monoclonal antibody:

LPS: Lipopolysaccharide; OMPs: Outer membrane protein

\section{Acknowledgements}

We feel gratitude in acknowledging Dr. Kathleen Laura Hefferon, Professor Cell and system biology, University of Toronto, Canada. For the critical review of the manuscript. The authors would also like to thank Professor Kathleen for their excellent help and appreciation.

\section{Funding}

No funding source is available.

\section{Availability of data and materials}

Data sharing not applicable to this article as no data sets were generated or analyzed during the current study.

\section{Authors' contributions}

The review article was envisaged by NA, the relevant researches were analyzed by SUR and BA. The manuscript was edited by NA and MIA. All the authors thoroughly read and approved the material for publication.

\section{Ethics approval and consent to participate}

Not applicable.

\section{Consent for publication}

Not applicable

\section{Competing interests}

The authors declare that they have no competing interests.

\section{Publisher's Note}

Springer Nature remains neutral with regard to jurisdictional claims in published maps and institutional affiliations.

\section{Author details}

${ }^{1}$ Institute of Microbiology, University of Agriculture, Faisalabad 3840, Pakistan. ${ }^{2}$ Institute of Physiology and Pharmacology, University of Agriculture, Faisalabad 3840, Pakistan.

Received: 29 January 2018 Accepted: 19 February 2018

Published online: 01 March 2018

\section{References}

1. Janda A, Bowen A, Greenspan NS, Casadevall A. Ig constant region effects on variable region structure and function. Front Microbiol. 2016;7:22.

2. Adachi M, Kurihara $Y$, Nojima H, Shitaka MT, Kamiya K, Umeyama $H$. Interaction between the antigen and antibody is controlled by the constant domains: normal mode dynamics of the HEL-HyHEL-10 complex. Protein Sci. 2003:12:2125-31.

3. Casadevall A, Janda A. Immunoglobulin isotype influences affinity and specificity. Proc Natl Acad Sci U S A. 2012;109:12272-3.

4. Eryilmaz E, Janda A, Kim J, Cordero RJB, Cowburn D, Casadevall A. Global structures of lgG isotypes expressing identical variable regions. Mol Immunol. 2013;56:10.

5. Sela-Culang I, Kunik V, Ofran Y. The structural basis of antibody-antigen recognition. Front Immunol. 2013;4:302.

6. Kieber-Emmons T, Monzavi-Karbassi B, Pashov A, Saha S, Murali R, Kohler H. The promise of the anti-idiotype concept. Front Oncol. 2012;2:196.

7. Venturini AC, Bresjanac M, Vranac T, Koren S, Narat M, Popovic M, Serbec VC. Anti-idiotypic antibodies: a new approach in prion research. BMC Immunol. 2009;10:16.

8. Vani J, Nayak R, Shaila MS. Maintenance of antigen-specific immunological memory through variable regions of heavy and light chains of anti-idiotypic antibody. Immunology. 2007;120:486-96.

9. Ponomarenko NA, Pillet D, Paon M, Vorobiev II, Smirnov IV, Adenier H, Avalle B, Kolesnikov AV, Kozyr AV, Thomas D, Gabibov AG, Friboulet A. AntiIdiotypic antibody mimics proteolytic function of parent antigen. Biochemistry. 2007:46:14598-609.

10. Keay S, Baldwin B. Anti-idiotype antibodies that mimic gp86 of human cytomegalovirus inhibit viral fusion but not attachment. J Virol. 1991;65:5124-8

11. Elias D, Cohen IR, Schechter $Y$, et al. Antibodies to insulin receptor followed by anti-idiotype. Antibodies to insulin in child with hypoglycemia. Diabetes. 1987;36:348-54. 
12. John IB, Seligmann EG. Neutrophil chemoattractant fMet-Leu-Phe receptor expression and ionic events following activation. In: Snyderman R, editor. Regulation of leukocyte function. Contemporary Topics in Immunobiol, vol. 3; 1984. p. 83-108.

13. Marasco WA, Becker EL. Anti-idiotype as antibody against the formyl peptide chemotaxis receptor of the neutrophil. J Immunol. 1982;128:963-8.

14. Baker JR, Yvonne GL, Burman KD. Production, isolation, and characterization of rabbit anti-Idiotypic antibodies directed against human Antithyrotrophin receptor antibodies. J Clin Invest. 1984;74:488-95.

15. Watts RA, Isenberg DA. Leading article: Idiotypes and anti-idiotypes: what are they trying to tell us? Ann Rheum Dis. 1988;47:705-7.

16. Jerne K, Cocteau J. Idiotypic networks and other preconceived ideas. Immunol Rev. 1984;79:5-24.

17. Langman RE, Cohn M. 'Thecomplete' idiotype network is an absurd immune system. Immunol Today. 1986;7:1-2.

18. Valderrama R, Eggers $A E$, Revan $S$, et al. Idiotypic control of the immune response. J Neuroimmunol. 1988;20:269-76.

19. Hong J, Zang YCQ, Tejada-Simon MV, Li S, Rivera VM, Killian J, Zhang JZ. Reactivity and regulatory properties of human anti-Idiotypic antibodies induced by T cell vaccination. J Immunol. 2000;165:6858-64.

20. Byung SK. Mechanisms of Idiotype suppression. In Vitro generation of Idiotype-specific suppressor T cells by anti-ldiotype antibodies and specific antigen. J Exp Med. 1979;149:1371-8.

21. Tzioufas AG, Routsias JG. Idiotype, anti-idiotype network of autoantibodies: Pathogenetic considerations and clinical application. Autoimmun Rev. 2010;9:631-3.

22. Perez A, Lombardero J, Mateo C, Mustelier G, Alfonso M, Vazquez AM, Perez R. Immunogenetic analysis of variable regions encoding $A B 1$ and g-type AB2 antibodies from the NeuGc-containing ganglioside family. Hybridoma. 2004; $20: 211-21$

23. Schrater AF, Goidl EA, Thorbecke GJ, Siskin AGW. Production of auto-antiIdiotypic antibody during the normal immune response to Tnp-Ficoll. J Exp Med. 1979;150:808-17.

24. Seledtsov VI, Seledtsova GV. A possible role for Idiotype/anti-idiotype B-T cell interactions in maintaining immune memory. Front Immunol. 2017;8:409.

25. Tanel A, Fonseca SG, Diab BY, Bordi R, Zeidan J, Shi Y, Benne C, Sékaly RP. Cellular and molecular mechanisms of memory T-cell survival. Expert Rev Vaccines. 2009;3:299-312.

26. Pereza A, Miera ES, Vispob NS, Vazqueza AM, Rodrıgueza RP. A monoclonal antibody against NeuGc-containing gangliosides contains a regulatory idiotope involved in the interaction with B and T cells. Mol Immunol. 2002;39:103-12.

27. Hiernaux JR. Idiotypic vaccines and infectious diseases. Infect Immun. 1988:1407-13.

28. Arif J, Rahman SU, Arshad M, Akhtar P. Immunepotentiation of outer membrane protein through anti-idiotype Pasteurella multocida vaccine in rabbits. Biologicals. 2013;41(6:339-44.

29. Hudson JAW, Rudy D, Gèrard $H$, et al. The anti-idiotypic antibody to chlamydial glycolipid exoantigen (GLXA) protects mice against genital infection with a human biovar of Chlamydia trachomatis. Vaccine. 2001;19:4061-71.

30. Pride MW, Shi H, Anchin JM, Linthicum DS, LoVerde PT, Thakur A, Thanavala Y. Molecular mimicry of hepatitis B surface antigen by an anti-idiotypederived synthetic peptide. Proc Natl Acad Sci U S A. 1992;89:11900-4.

31. Muller S, Parsons MS, Kohler H, Grant M. The significance of a common Idiotype (1F7) on antibodies against human immune deficiency virus type 1 and hepatitis C virus. Front Oncol. 2016;6:11.

32. Westerink MAJ, Apicella MA. Anti-idiotypic antibodies as vaccines against carbohydrate antigens. Springer Semin Immunopathol. 1993;15:227-34.

33. Mutapi F, Billingsley PF, Secor WE. Infection and treatment immunizations for successful parasite vaccines. Cell Press. 2013;29:135-41.

34. Kato T, Takazoe I, Okuda K. Protection of mice against the lethal toxicity of a lipopolysaccharide (LPS) by immunization with anti-idiotype antibody to a monoclonal antibody to lipid a from Eikenella corrodens LPS. Infect Immun. 1990;58:416-20.

35. Ladjemi MZ. Anti-idiotypic antibodies as cancer vaccines: achievements and future improvements. Front Oncol. 2012;2:158.

36. Franki SN, Steward KK, Betting DJ, Kafi K, Yamada RE, Timmerman JM. Dendritic cells loaded with apoptotic antibody-coated tumor cells provide protective immunity against B-cell lymphoma in vivo. Blood. 2008;111:1504-11.
37. Foon KA, Chakraborty M, John WJ, Sherratt A, Köhler H, Bhattacharya-Chatterjee M. Immune response to the carcinoembryonic antigen in patients treated with an anti-idiotype antibody vaccine. J Clin Invest. 1995;96:334-42.

38. Grisham RN, Berek J, Pfisterer J, Sabbatini P. Abagovomab: an anti-idiotypic CA-125 targeted immunotherapeutic agent for ovarian cancer. Immunotherapy. 2011;3:153-62.

39. Foon KA, Lutzky J, Baral RN, Yannelli JR, Hutchins L, Teitelbaum A. Clinical and immune responses in advanced melanoma patients immunized with an anti-Idiotype antibody mimicking Disialoganglioside GD2. J Clin Oncologia. 2000;18:376.

40. Gomez DE, Vázquez AM, Alonso DF, Macías A. Anti-idiotype antibodies in cancer treatment. Front Oncol. 2013;3:37.

41. Gómez RE, Ardigo ML. Anti-idiotype antibodies in cancer treatment: the pharmaceutical industry perspective. Front Oncol. 2012;2:147.

42. Llanos A, Savignano M, Cinat G. Maintenance treatment with chemotherapy and immunotherapy in non-small cell lung cancer: a case report. Front Oncol. 2012;2:152.

43. Nepom GT, Nelson KA, Holbeck SL, Hellström I, Hellström KE. Induction of immunity to a human tumor marker by in vivo administration of anti-idiotypic antibodies in mice. Proc Natl Acad Sci U S A. 1984;81:2864-7.

44. Dunn PL, Johnson CA, Styles JM, Pease \& Dean CJ. Vaccination with syngeneic monoclonal anti-idiotype protects against a tumour challenge. Immunology 1987; 60: 181-186.

45. Ondondo B, Jones E, Hindley J, et al. Progression of carcinogen-induced fibrosarcomas is associated with the accumulation of naïve CD4+ T cells via blood vessels and lymphatics. Int J Cancer. 2014;134:2156-67.

46. Basak S, Eck S, Gutzmer R, et al. Colorectal cancer vaccines: antiidiotypic antibody, recombinant protein, and viral vector. Ann N Y Acad Sci. 2000;910:237-52.

47. Wang X, Ko EC, Peng L, Gillies SD, Ferrone S. Human high molecular weight melanoma-associated antigen mimicry by mouse anti-idiotypic monoclonal antibody MK2-23: enhancement of immunogenicity of anti-idiotypic monoclonal antibody MK2-23 by fusion with interleukin 2. Cancer Res. 2005;65:6976-83.

48. Weiner LM, Dhodapkar MV, Ferrone S. Monoclonal antibodies for cancer immunotherapy. Lancet. 2010;373:1033-40.

49. Ma J, Zhou L, Wang D. Functional mimicry of an anti-idiotypic antibody to nominal antigen on cellular response. Jpn J Cancer Res. 2002;93:78-84.

50. Fredriksen AB, Sandlie I, Bogen B. Targeted DNA vaccines for enhanced induction of idiotype-specific B and T cells. Front Oncol. 2012;2:154.

51. Baskar S, Kobrin CB, Kwak LW. Autologous lymphoma vaccines induce human $\mathrm{T}$ cell responses against multiple, unique epitopes. J Clin Invest. 2004;113:1498-510.

52. Inoges S, Lopez-Diaz de Cerio A, Villanueva H, Pastor F, Soria E, Bendandi M. Idiotype vaccines for lymphoma: potential factors predicting the induction of immune responses. World J Clin Oncol. 2011;10:237-44.

53. Gaida FJ, Fenger U, Wagener C, Neumaier M. A monoclonal anti-idiotypic antibody bearing the image of an epitope specific to the human carcinoembryonic antigen. Inter. J. Of. Cancer. 1992;51:459-65.

54. Virot E, Duclos A, Adelaide $L$, et al. Autoimmune diseases and HIV infection. Medicine (Baltimore). 2017;96(4):e5769.

55. Maurizio B. Idiotype vaccines for lymphoma: proof-of-principles and clinical trial failures. Nat Rev Cancer. 2009;9:675-81.

56. Timmerman JM, Singh G, Hermanson G, et al. Immunogenicity of a plasmid DNA vaccine encoding chimeric ldiotype in patients with B-cell lymphoma. Cancer Res. 2002;62:5845-52.

57. Magliani W, Conti S, de Bernardis F, et al. Therapeutic potential of antiidiotypic single chain antibodies with yeast killer toxin activity. Nat Biotechnol. 1997;15:155-8. 